\title{
The Effect of Gamma Irradiation on the Essential Oils and Antioxidants in Dried Thyme
}

\author{
Amal N. Al-Kuraieef ${ }^{a}$ And Amal H. Alshawi ${ }^{a^{*}}$ \\ ${ }^{a}$ Princess Norah bint Abdulrahman University, Nutrition and Food Science Department, 84428 Riyadh, KSA \\ * Corresponding author \\ a_alshawi@hotmail.com \\ TEL: +966118237491
}

Received: 27 September 2018; Published online: 18 April 2020

\begin{abstract}
This research was undertaken to investigate the effect of gamma rays at dose rates of 5.0, 10.0 and $15.0 \mathrm{kGy}$ on the chemical composition of essential oils, total antioxidants, total flavonoids and total phenols, as well as the antioxidant activity and the thiobarbituric acid (TBA) and the free radicalscavenging activity (DPPH) of thyme. Radiation processing increased the total phenols, total flavonoids and total antioxidants of thyme, and moderate changes were detected at doses of 5 and $10 \mathrm{kGy}$ for the essential oils. Thymol was sensitive to irradiation, especially at $15.0 \mathrm{kGy}$ doses. In addition, the evaluation of antioxidant activity using DPPH radical-scavenging activity indicated some decreases of antioxidant activity in irradiated samples, while thyme exposed to doses of 10 and $15 \mathrm{kGy}$ exhibited a significant increase in TBA values. The irradiation process can facilitate the utilisation of thyme as a preservative ingredient in the food and pharmaceutical industry.
\end{abstract}

Keywords: Irradiation; Thyme; Essential oil; Antioxidant; Flavonoid; Phenol

\section{Introduction}

The long history of herbs and spices has demonstrated their safe usage and excellent source for antioxidants. Thyme (Thymus vulgaris L.) is an herb descended from the Lamiaceae family. Thyme can be consumed as a whole spice/herb, or it can be ground, extracted, encapsulated or used as an emulsion. Thyme is characterized by its phytochemicals, efficacy as an antioxidant, and possession of phenolic compounds and flavonoids. Therefore, it has been determined to be a prominent herb from a medicinal and aromatic perspective (Embuscado, 2015).

Antioxidants are essential substances that inhibit other compounds from being oxidized (Aqil, Ahmad \& Mehmood, 2006). Furthermore, the antioxidants produced by spices and herbs usually act with free radicals created in the initiation phase of autoxidation (Lee, Umano, Shibamoto \& Lee, 2005). The antioxidants from thyme methanolic extracts can significantly prevent peroxidation in lipids (Fejes et al., 2000).

DPPH radical-scavenging activity is employed worldwide as an antioxidant activity assay; using this assay, a correlation between phenolic content and free radical-scavenging in nine plant extracts was observed. The chemical analysis of the extracts indicated the presence of phenolics, tannins, flavonoids, glycosides and alkaloids. The phenolic concentrations in dry plant extracts varied from 28.66 to $169.67 \mathrm{mg} \mathrm{g}^{-1}$ (Aqil et al., 2006).

Thyme's essential oils are distinguished by having a high content of important compounds, such as thymol, carvacrol, y-terpinene and p-cymene. These compounds range from $57.3 \%$ to $62.5 \%$ of the total oil content (Senatore, 1996). How- 


\section{Nomenclature}

TBA Thiobarbituric acid number

DPPH 2, 2-diphenyl-1-picrylhydrazyl

GLC gas-liquid chromatography
FID flame ionization detectors

GAE Gallic acid equivalent

IC 50 The half maximal inhibitory concentration ever, it has been reported that thyme contains thymol and carvacrol in the $44-60 \%$ and 2.2 $4.2 \%$ range, respectively, which can therefore be used to control lipid oxidation in foods (Alcicek, 2011). In addition, the prominent compounds quantitatively constitute approximately three-quarters of the total volatile compounds: thymol (72\%) and carvacrol (isothymol) (5.7\%) (Baranauskiene, Venskutonis, Viskelis \& Dambrauskiene, 2003).

Although synthetic antioxidants can be used to prevent oxidation, they may not contribute additional nutritional benefits. On the contrary, the body can easily assimilate natural antioxidants, which are produced by spices and herbs, such as thyme (Embuscado, 2015).

Furthermore, thyme has long been used to preserve food and beverages via its phytochemicals. It has also been used as a natural food ingredient due to its colour and aroma (Alcicek, 2011).

Numerous aromatic substances have been generated from thyme extract. The extract consists of three acids, three aldehydes, four ketones and esters, seven alcohols, 14 aromatic compounds, 16 sesquiterpenes and 43 monoterpenes. In fact, the primary aroma in thyme is derived from phenolic compounds (Baranauskiene et al., 2003).

Food irradiation is a process involving the use of ionizing radiation, such as gamma rays, to generate various beneficial effects. The process can minimise post-harvest and storage losses, ensure hygienic quality, extend shelf life, simplify the trade of food products and enhance the parasitological and microbiological safety of foods by diminishing the effect of spoilage from microorganisms. Moreover, dried foods, herbs and spices can be exposed to ionizing radiation as an accredited preservation process (Nagy, Solar, Sontag \& Koenig, 2011). Any of these effects depends on the radiation dose absorbed. Among all irradiated commercial products, irradiated spices and vegetable seasonings are the most commonly used. However, for commercial use, the typical dose is 10 kGy (Shurong, Meixu \& Chuanyao, 2006).

Due to the importance of antioxidants in herbs and spices, Nagy et al. (2011) confirmed that radiation has no significant effect on their antioxidant properties nor on the division in the bonds of the glycoside. In fact, many types of herbs and spices exhibit a level of radioprotection even when consumed before radiation exposure (Farag, 2013).

The present study aimed to investigate the effect of gamma rays at dose rates of 5, 10 and $15 \mathrm{kGy}$ on the chemical composition of essential oils, total antioxidants, total flavonoids and total phenols, as well as on the antioxidant activity of dried thyme (Thymus vulgaris L.).

\section{Materials and Methods}

\section{$2.1 \quad$ Plant material}

Samples of fresh aerial parts of thyme (Thymus vulgaris L.) were collected from a grocery market in Riyadh city, Saudi Arabia. The samples were prepared by washing and drying them in the shade. Then, 250 grams of plant material were placed in a series of polyethylene bags. For the chemical analysis, the bags were divided into groups; each sample had five replicates. 


\section{$2.2 \quad$ Irradiation process}

A Gamma Cell was used for irradiation, delivering a dose rate of $14.2514 \mathrm{kGy} \mathrm{h}^{-1}$ at the time of the experiment. (Model Gamma Cell220 from MDS, Nordion Initial, Canada: Activity source (Co-60) was $24,000 \mathrm{Ci}$ of the production in December 1993) The Gamma Cell at King Abdul Aziz City for Science and Technology in Riyadh was used to expose the thyme samples, except the control sample, to 5,10 or $15 \mathrm{kGy}$ of gamma radiation.

\subsection{Chemical analysis}

After extracting the essential oils from the treated samples of thyme, the samples were analysed via gas-liquid chromatography (GLC).

\subsection{Essential oil extraction}

Each sample of dried thyme was placed in a flask filled with double-distilled water. Steam distillation was continuously applied for three hours until the oil was isolated; then, it was dried over anhydrous sodium sulphate (Pellegrini et al., 2003).

\subsection{GLC analysis}

Authentic essential oils were obtained from Dragoc (Holzminden, Germany) and were analysed using GC Pye-Unicam gas chromatography dualflame ionization detectors (FID) with a chromate graph fitted with a coiled glass column $(1.5 \mathrm{~m}$ x $4 \mathrm{~mm}$ ) and packed with a 100-120 diatomitec mesh coated with $10 \%$ PEGA. The oven was programmed to gradually increase in temperature from $60{ }^{\circ} \mathrm{C}$ to $180{ }^{\circ} \mathrm{C}$ by $4{ }^{\circ} \mathrm{C} \mathrm{min}-1$, and the isothermal process was continued for 15 minutes at $180{ }^{\circ} \mathrm{C}$. The temperature for the detector was $220^{\circ} \mathrm{C}$, while that for the injector was $30^{\circ} \mathrm{C}$. The gas flow rate was $33 \mathrm{~mL} \mathrm{~min}{ }^{-1}$ for hydrogen and $30 \mathrm{~mL} \mathrm{~min}{ }^{-1}$ for nitrogen and air. After mixing the extracted essential oils with their main components, they were injected into the GLC to verify the resultant peaks (Jayaprakasha, Rao \& Sakariah, 2002). For accuracy, the analysis was repeated five times.

\subsection{Preparing samples for chemical analysis}

Thirty grams of dried thyme was exposed to radiation in various doses and then weighed; they were then extracted by mixing them with distilled water, then stirring and turning them for 15 minutes, after which they were separated in centrifugal concentrators for 10 minutes $(1000 \times$ g). Afterwards, they were re-extracted several times and kept as an aqueous extract for subsequent tests. After filtering and extraction, 110 $\mathrm{mL}$ were obtained, and five replicates were made after each test analysis (Pellegrini et al., 2003).

\subsection{Total antioxidant activity}

The antioxidant content was estimated as equivalent to quercetin, which was used by Meda, Lamien, Romito, Millogo and Nacoulma (2005), by adding $0.75 \mathrm{~mL}$ of aqueous extract to $1.5 \mathrm{~mL}$ of a 2,2,-diphenyl-2-picryl-hydrazil (DPPH) solution in methanol at a $0.02-\mathrm{mg} \mathrm{mL}^{-1}$ concentration. Then, the mixture was left at room temperature for 15 minutes, after which the absorbance was read via a spectrophotometer with a wavelength of $517 \mathrm{~nm}$ and with $0.75 \mathrm{~mL}$ of water $+1.5 \mathrm{~mL}$ of methanol as a blank. The results were compared with similar cases when using the quercetin $6 \mathrm{mg} \mathrm{mL}^{-1}$ concentration.

\subsection{Total phenolic assay}

Determination the total phenolic content of thyme samples was accomplished using the FolinCiocalteu assay (Singleton \& Rossi, 1965). One $\mathrm{mL}$ of the extract or a standard solution of gallic acid was added to $9 \mathrm{~mL}$ of distilled water in a $25 \mathrm{~mL}$ volumetric flask. A reagent blank was prepared using distilled water. The mixture was shaken after adding $1 \mathrm{~mL}$ of FolinCiocalteu phenol reagent. Then, $10 \mathrm{~mL}$ of $7 \%$ $\mathrm{Na}_{2} \mathrm{CO}_{3}$ solution was added to the mixture after 5 minutes. After incubating the mixture at room temperature for 90 minutes, the prepared reagent blank had a specified absorbance at $750 \mathrm{~nm}$. One $\mathrm{mg}$ of gallic acid equivalent to GAE. $100 \mathrm{~g}^{-1}$ of dried weight of thyme was used to express the 
total phenolic content. For each determination, five samples were used (Meda et al., 2005).

\subsection{Total flavonoid assay}

An aluminum chloride solution $(5 \mathrm{~mL})$ was added to methanol at $2 \%$, and the mixture was left for 10 minutes. Absorbance was read at a wavelength of $415 \mathrm{~nm}$. A mixture of $5 \mathrm{~mL}$ of each methanol and the extraction was used as a blank. The results were then compared to quercetin at a concentration of $6.25 \mu \mathrm{g} \mathrm{mL}{ }^{-1}$. For each determination, five samples were used (Meda et al., 2005).

\subsection{Radical scavenging activity}

Antioxidant activity was estimated using the method of Meda et al. (2005), with some modification, i.e., the use of 2,2-diphenyl-1picrylhydrazyl (DPPH). The formula used to calculate the activity was:

$$
\text { \% Inhibition }=\left[(A C-A S) \cdot A C^{-1}\right] \times 100
$$

AC: the absorbance value of the control.

AS: the absorbance value of the test solution. Subsequently, the half maximal inhibitory concentration $\mathrm{IC}_{50}$ was calculated by evaluating the DPPH radical scavenging activity at different concentrations of the water extracts.

\subsection{Thiobarbituric acid value}

The analysis was accomplished by the oxidative reaction products, which were determined as the thiobarbituric acid number (TBA). Two $\mathrm{mL}$ of trichloroacetic acid (20\% aq.) and $2 \mathrm{~mL}$ of thiobarbituric acid solution ( $0.67 \%$ aq.) were added to $1 \mathrm{~mL}$ of thyme extract. The mixture was submerged in a boiling water bath for 10 minutes. Then, the mixture was cooled to ambient temperature before centrifugation of the $500 \mathrm{~g}$ mixture at $3000 \mathrm{rpm}$ for 20 minutes. For each determination, five samples were used (Zin, Abdul-Hamid \& Osman, 2002).

\subsection{Statistical analysis}

The data from the experiment were analysed using SAS system version 9.1.3. (Cary, NC), to calculate means, standard deviations and least significant differences. Results were expressed as mean \pm (standard deviation) (SD) considering a $\mathrm{P}$ value of $\leq 0.05$ as significant (Ott, 1984).

\section{Results and Discussion}

\subsection{Essential oils}

At low doses, the irradiation process is considered to be a cold, physical treatment for food because no significant heating occurs as a result of treating the samples. Therefore, irradiation has no direct effect on flavour compounds (AlBachir, 2016).

The important compounds were thymol (39.52 \pm $\left.0.15 \mathrm{mg} .100 \mathrm{~g}^{-1}\right)$, p-cymene $(21.60 \pm 0.28 \mathrm{mg}$ $\left..100 \mathrm{~g}^{1}\right)$ and y-terpinene $(18.41 \pm 0.07 \mathrm{mg} .100$ $\mathrm{g}^{-1}$ ), which constituted almost three-quarters of the total quantified volatiles, followed by monoterpenes, P-caryophyllene $(2.71 \pm 0.08 \mathrm{mg}$ $\left..100 \mathrm{~g}^{-1}\right)$, carvacrol $\left(2.45 \pm 0.07 \mathrm{mg} .100 \mathrm{~g}^{-1}\right)$ and trans-sabinene hydrate $(2.30 \pm 0.14 \mathrm{mg}$ $.100 \mathrm{~g}^{-1}$ ). Major volatile constituents, such as thymol, y-terpinene and carvacrol, were distinctive for T. vulgaris species and were also found as major compounds in other published results (Baranauskiene et al., 2003).

The results showed that radiation had significant effects on the concentrations of some compounds in the content of the dried thyme before and after different radiation doses. Table 1 shows the chemical composition of the essential oils of thyme after radiation at 5, 10 and $15 \mathrm{kGy}$ compared with non-irradiated samples.

Thymol was stable when exposed to doses of 5 and $10 \mathrm{kGy}(39.0 \pm 0.165,39.11 \pm 0.087$ $\mathrm{mg} .100 \mathrm{~g}^{-1}$, respectively), yet its concentration decreased significantly when exposed to higher doses as compared with non-irradiated samples $\left(38.50 \pm 0.068,39.52 \pm 0.150 \mathrm{mg} .100 \mathrm{~g}^{-1}\right.$, respectively). This result is consistent with the determination of $10 \mathrm{kGy}$ as the commercial dose of dried spices, set by the World Health Organization World Health Organization (1988), needed 
to reduce the loss of thymol, which is considered one of the most important compounds for inhibiting oxidation (Lee et al., 2005).

The concentrations of trans-sabinene hydrate were stable when exposed to doses of 5,10 and $15 \mathrm{kGy}(2.29 \pm 0.224,2.28 \pm 0.035,2.18 \pm 0.012$ $\mathrm{mg} .100 \mathrm{~g}^{-1}$, respectively) compared with nonirradiated samples $\left(2.30 \pm 0.141 \mathrm{mg} .100 \mathrm{~g}^{-1}\right)$.

The concentrations of $p$-cymene increased after exposure to a dose of $10 \mathrm{kGy}(22.24 \pm 0.230 \mathrm{mg}$ $\left..100 \mathrm{~g}^{-1}\right)$; a tendency towards reduction after exposure to a dose of $15 \mathrm{kGy}(22.20 \pm 0.135 \mathrm{mg} .100$ $\mathrm{g}^{-1}$ ) was also shown. The lack, or small effect, of irradiation on the thyme aroma compounds is in agreement with Pereira et al. (2016).

The concentrations of y-terpinene decreased in samples exposed to a dose of $5 \mathrm{kGy}$ compared with the control sample, while there was no obvious difference when exposed to doses of 10 and 15 kGy. There was also a reduction of carvacrol for all samples compared to the control, with the least-affected samples receiving a dose of $10 \mathrm{kGy}$. Generally, irradiation adversely affected the total content of the essential oils of dried thyme.

\subsection{The total phenols, total flavonoids and total antioxidants}

The results show the effects of Y-irradiation treatments on total phenols, flavonoids and antioxidants (Table 2).

The results illustrated that irradiated dried thyme at 5, 10 and $15 \mathrm{kGy}$ had higher levels of phenolic compounds than the non-irradiated control sample in the methanolic extract. The significant increase in the phenolic content was $4954.67 \pm 0.072,5010.71 \pm 0.015$ and $4986.22 \pm$ $0.075 \mathrm{mg} .100 \mathrm{~g}^{-1}$ for the samples irradiated at 5, 10 and $15 \mathrm{kGy}$, respectively, compared to their content in the non-irradiated control $(4925.73 \pm$ $\left.0.048 \mathrm{mg} .100 \mathrm{~g}^{-1}\right)$. The highest total phenolic content occurred at a dose of $10 \mathrm{kGy}$.

The increase in the total phenolic content could be attributed to the inducement of a chemical reaction that decomposed the large molecules into small molecules, which are easily soluble in methanol and thus produce more solutes. This explanation is correlated with Huang and Mau (2006) findings. Moreover, Kim, Yook and Byun (2000) found that the total methanolic extract in 15 kinds of Korean medicinal herbs using various solvents increased by $5-25 \%$ at a dose of $10 \mathrm{kGy}$ of $\gamma$-irradiation.

Gamma radiation causes an increase of soluble phenols in some spice extracts (Variyar, Limaye \& Sharma, 2004). On the contrary, in some studies, no significant change was observed when comparing the phenolic content in the non-irradiated samples with that of irradiated samples at a dose of $20 \mathrm{kGy}$ in Agaricus blazei (Huang \& Mau, 2007), 30 kGy in Rosmarinus officinalis L. powder (Perez, Calderon \& Croci, 2007), and 5 to $30 \mathrm{kGy}$ in Carum carvi L. and Laurus nobilis L. (Polovka \& Suhaj, 2010). The total flavonoid content for thyme irradiated with a dose of 5,10 and $15 \mathrm{kGy}$ increased significantly by $43.66 \pm 0.035,47.42 \pm 0.043$ and 40.81 $\pm 0.039 \mathrm{mg} .100 \mathrm{~g}^{-1}$, respectively. Whereas in the non-irradiated sample, it was $36.41 \pm 0.026$ $\mathrm{mg} .100 \mathrm{~g}^{-1}$. The maximum increase was obtained at the $10 \mathrm{kGy}$ dose: $47.42 \pm 0.043 \mathrm{mg}$ $.100 \mathrm{~g}^{-1}$. However, these findings are in contrast to those of Zhu, Cai, Bao and Corke (2010), who reported a decrease in flavonoid content at a dose of $2 \mathrm{kGy}$ and a minimum content at a dose of 10 kGy.

Total antioxidant content for thyme irradiated with 5, 10 and $15 \mathrm{kGy}$ doses significantly increased, reaching levels of $2402 \pm 0.880,2419.66$ \pm 0.152 and $2408 \pm 0.234 \mathrm{mg} .100 \mathrm{~g}^{-1}$, respectively. Whereas in the non-irradiated sample, it was $2392.25 \pm 0.027 \mathrm{mg} .100 \mathrm{~g}^{-1}$, with a maximum increase obtained at a 10 kGy dose, $2419.66 \pm 0.152 \mathrm{mg} .100 \mathrm{~g}^{-1}$, as shown in Table 2. However, Taipina, Lamardo, Rodas and del Mastro (2009) reported no antioxidant content loss when irradiating pecan nuts with doses between 1-3 kGy.

The DPPH radical-scavenging activity and $\mathrm{IC}_{50}$ for irradiated thyme are shown compared with non-irradiated samples in Table 3.

The results indicate that the DPPH radicalscavenging activity of methanolic thyme extracts for an irradiated sample at doses of 5, 10 and 15 kGy were $0.58 \pm 0.001,0.56 \pm 0.001$ and 0.60 $\pm 0.003 \%$ less than that for the non-irradiated control: $0.62 \pm 0.001 \%$. A similar trend was observed in Abolhasani, Barzegar and Sahari 
Table 1: The chemical composition of the essential oils of dried thyme irradiated with various doses of $\gamma$-irradiation

\begin{tabular}{llllll}
\hline \multirow{2}{*}{ Compound } & \multicolumn{5}{c}{ Quantity $\left(\mathrm{mg} .100 \mathrm{~g}^{-1}\right.$ dry weight) } \\
& Control & $5 \mathrm{KGy}$ & Radiation Dose $(\mathrm{kGy})$ & \\
& $1.61 \pm 0.175$ & $1.75 \pm 0.156$ & $1.99 \pm 0.069$ & $2.10 \pm 0.025$ & 0.00 \\
a-Thujene & $1.32 \pm 0.109$ & $1.90 \pm 0.069$ & $2.16 \pm 0.089$ & $2.01 \pm 0.022$ & 0.00 \\
a-Pinene & $2.11 \pm 0.077$ & $2.15 \pm 0.036$ & $2.62 \pm 0.168$ & $2.60 \pm 0.115$ & 0.00 \\
Myrcene & $1.74 \pm 0.139$ & $1.99 \pm 0.010$ & $2.23 \pm 0.154$ & $2.33 \pm 0.064$ & 0.00 \\
a-Teroinene & $21.60 \pm 0.282$ & $21.90 \pm 0.07$ & $22.24 \pm 0.230$ & $22.20 \pm 0.135$ & 0.00 \\
p-cymene & $18.41 \pm 0.076$ & $18.21 \pm 0.044$ & $18.39 \pm 0.048$ & $18.36 \pm 0.038$ & 0.00 \\
y-Terpinene & $2.30 \pm 0.141$ & $2.29 \pm 0.224$ & $2.28 \pm 0.035$ & $2.18 \pm 0.012$ & $0.482^{*}$ \\
trans-Sabinene hydrate & $1.42 \pm 0.025$ & $1.30 \pm 0.052$ & $1.21 \pm 0.06$ & $1.15 \pm 0.018$ & 0.00 \\
Linalol & $1.18 \pm 0.01$ & $1.22 \pm 0.014$ & $1.01 \pm 0.01$ & $0.98 \pm 0.034$ & 0.00 \\
Borneol & $39.52 \pm 0.150$ & $39.0 \pm 0.165$ & $39.11 \pm 0.087$ & $38.50 \pm 0.068$ & 0.001 \\
Thymol & $2.45 \pm 0.079$ & $1.14 \pm 0.046$ & $1.76 \pm 0.063$ & $1.55 \pm 0.044$ & 0.00 \\
Carvacrol & $2.71 \pm 0.08$ & $3.55 \pm 0.015$ & $2.30 \pm 0.041$ & $2.13 \pm 0.078$ & 0.00 \\
P-Caryophyllene & $96.37 \pm 1.288$ & $96.436 \pm 1.20$ & $97.33 \pm 0.571$ & $96.09 \pm 0.104$ & 0.212 \\
Total & &
\end{tabular}

$(*)$ There was no significant difference between trans-Sabinene hydrate compound groups.

Values expressed as means $\pm \mathrm{SD}$ (standard deviation). Repetition number $=5$.

Values are significant differences $(\mathrm{P} \leq 0.001)$.

Table 2: Total phenols, flavonoids and antioxidants of methanolic thyme extracts irradiated with doses of gamma radiation

\begin{tabular}{llll}
\hline \multirow{2}{*}{ Radiation Dose (kGy) } & \multicolumn{3}{c}{ Contents $\left(\mathrm{mg} .100 \mathrm{~g}^{-1}\right.$ dry weight $)$} \\
& Total Phenols & Total Flavonoids & Total Antioxidants \\
\hline Control & $4925.73 \pm 0.048$ & $36.41 \pm 0.026$ & $2392.25 \pm 0.027$ \\
$5 \mathrm{kGy}$ & $4954.67 \pm 0.072$ & $43.66 \pm 0.035$ & $2402 \pm 0.880$ \\
$10 \mathrm{kGy}$ & $5010.71 \pm 0.015$ & $47.42 \pm 0.043$ & $2419.66 \pm 0.152$ \\
$15 \mathrm{kGy}$ & $4986.22 \pm 0.075$ & $40.81 \pm 0.039$ & $2408 \pm 0.234$ \\
$P$ - Value & 0.00 & 0.00 & 0.00 \\
\hline
\end{tabular}

Values expressed as means \pm SD. Repetition number $=5$.

Values are significant differences $(\mathrm{P} \leq 0.05)$. 
The effect of gamma irradiation on thyme $\mid 209$

Table 3: Scavenging activity and $\mathrm{IC}_{50}$ values of methanolic extract of thyme irradiated $\left(10 \mathrm{mg} \mathrm{mL}^{-1}\right)$ against DPPH radicals

\begin{tabular}{lll}
\hline Radiation Dose (kGy) & \% of DPPH scavenging activity & $\mathrm{IC}_{50}(\mathrm{mg} \mathrm{mL}$ \\
\hline Control & $0.62 \pm 0.001$ & $0.27 \pm 0.002$ \\
5 & $0.58 \pm 0.001$ & $0.46 \pm 0.001$ \\
10 & $0.56 \pm 0.001$ & $0.51 \pm 0.001$ \\
15 & $0.60 \pm 0.003$ & $0.37 \pm 0.001$ \\
$P$ - Value & 0.00 & 0.00 \\
\hline $\mathrm{IC}_{50}$ value: the effective concentration at which the antioxidant activity was
\end{tabular}

$50 \%$; the $(\mathrm{DPPH})$ radical was scavenged by $50 \%$.

Values expressed as means $\pm \mathrm{SD}$. Repetition number $=5$.

Values are significant differences $(\mathrm{P} \leq 0.05)$.

Table 4: TBA values of methanolic extract of thyme as a function of irradiation dose.

\begin{tabular}{ll}
\hline Radiation Dose $(\mathrm{kGy})$ & TBA number $\left(\mathrm{A}_{532}\right)$ mean $\pm \mathrm{SD}$ \\
\hline Control & $0.77 \pm 0.002$ \\
5 & $0.51 \pm 0.002$ \\
10 & $0.98 \pm 0.003$ \\
15 & $0.90 \pm 0.003$ \\
$P$ - Value & 0.00 \\
\hline
\end{tabular}

Values expressed as means \pm SD. Repetition number $=5$.

Values are significant differences $(\mathrm{P} \leq 0.05)$.

(2018), who found that DPPH activity decreased for irradiated pistachio green hull extracts at a dose of $10 \mathrm{kGy}$, then increased at a dose of 20 kGy. In contrast, there was an increase in the $\mathrm{IC}_{50}$ values of methanolic thyme extracts for the same doses, with the highest value recorded at a dose of $10 \mathrm{kGy}$.

A study conducted by Huang and Mau (2006) revealed that DPPH radical-scavenging activity exhibited no significant change as a result of irradiating freeze-dried mushrooms at doses from 2.5 to $20 \mathrm{kGy}$. Conversely, some studies reported an increase in DPPH radical-scavenging activity as a result of irradiating soybeans, green tea leaf extracts and rosemary leaf powder extracts at doses of 0.5-5 kGy, 10-20 kGy and $30 \mathrm{kGy}$, respectively (Jo, Son, Lee \& Byun, 2003; Perez et al., 2007; Variyar et al., 2004).

Table 4 shows that exposing thyme to doses of 10 and $15 \mathrm{kGy}$ gave a significant increase in the TBA numbers, which reached $0.98 \pm 0.003$ and
$0.90 \pm 0.003$, respectively. On the other hand, at $5 \mathrm{kGy}$, the TBA number decreased to $0.51 \pm 0.00$ compared to the control sample, which was 0.77 \pm 0.002 . This result agreed with Suhaj, Rácová, Polovka and Brezová (2006), who studied black pepper methanolic extract irradiated at doses ranging from 5-30 kGy. Moreover, the current results agreed with Polovka and Suhaj (2010), who reported that the highest value for the TBA of irradiated caraway samples was achieved at a dose of $10 \mathrm{kGy}$.

An analysis of some irradiated edible and medicinal herb extracts at doses of 10,20 and 30 kGy showed a change in the active components (Koseki et al., 2002). Under their experimental conditions, the only dose that had an inducement to the chemical substances of the extracts was at $10 \mathrm{kGy}$. 


\section{Conclusions}

Radiation processing increased the total phenols, total flavonoids and total antioxidants of thyme, with moderate changes detected at doses of 5 and $10 \mathrm{kGy}$ for the essential oils. Thymol was sensitive to irradiation, especially at a $15.0 \mathrm{kGy}$ dose. In addition, the evaluation of antioxidant activity using DPPH radical-scavenging activity indicated some loss of antioxidant activity in irradiated samples, while exposing thyme to doses of 10 and $15 \mathrm{kGy}$ significantly increased the TBA numbers.

\section{Acknowledgements}

This research did not receive any specific grant from funding agencies in the public, commercial or not-for-profit sectors.

\section{References}

Abolhasani, A., Barzegar, M. \& Sahari, M. A. (2018). Effect of gamma irradiation on the extraction yield, antioxidant, and antityrosinase activities of pistachio green hull extract. Radiation Physics and Chemistry, 144, 373-378. doi:10.1016/j.radphyschem. 2017.09.025

Alcicek, Z. (2011). The effects of thyme (thymus vulgaris 1.) oil concentration on liquidsmoked vacuum-packed rainbow trout (oncorhynchus mykiss walbaum, 1792) fillets during chilled storage. Food Chemistry, 128(3), 683-688. doi:10.1016/j.foodchem. 2011.03.087

Aqil, F., Ahmad, I. \& Mehmood, Z. (2006). Antioxidant and free radical scavenging properties of twelve traditionally used indian medicinal plants. Turkish Journal of Biology, 30, 177-183.

Al-Bachir, M. (2016). Some microbial, chemical and sensorial properties of gamma irradiated sesame (sesamum indicum l.) seeds. Food Chemistry, 197(A), 191-197. doi:10. 1016/j.foodchem.2015.10.094
Baranauskiene, R., Venskutonis, P. R., Viskelis, P. \& Dambrauskiene, E. (2003). Influence of nitrogen fertilizers on the yield and composition of thyme (thymus vulgaris). Journal of Agricultural and Food Chemistry, 51(26), 7751-7758. doi:10 . $1021 /$ jf0303316

Embuscado, M. E. (2015). Spices and herbs: Natural sources of antioxidants - a mini review. Journal of Functional Foods, 18(B), 811819. doi:10.1016/j.jff.2015.03.005

Farag, M. F. S. (2013). Utilization of basil extract as a radioprotector in male rats. Arab $J \mathrm{Sci}$ Appl, 46, 274-281.

Fejes, S., Blazovics, A., Lemberkovics, E., Petri, G., Szoke, E. \& Kery, A. (2000). Free radical scavenging and membrane protective effects of methanol extracts from anthriscus cerefolium l. (hoffm.) and petroselinum crispum (mill.) nym. ex a. w. hill. Phytotherapy Research, 14(5), 362365. doi:10 . 1002 / 1099 - 1573(200008) 14 : 5〈362::AID-PTR554〉3.0.CO;2-G

Huang, S.-J. \& Mau, J.-L. (2006). Antioxidant properties of methanolic extracts from agaricus blazei with various doses of gamma-irradiation. LWT - Food Science and Technology, 39, 707-716. doi:10.1016/ j.lwt.2005.06.001

Huang, S.-J. \& Mau, J.-L. (2007). Antioxidant properties of methanolic extract from antrodia camphorate with various doses of ??radiation. Food Chemistry, 105, 1702-1710. doi:10.1016/j.foodchem.2007.04.046

Jayaprakasha, G. K., Rao, L. J. \& Sakariah, K. K. (2002). Chemical composition of volatile oil from cinnamomum zeylanicum buds. Zeitschrift Fur Naturforschung $C$ a Journal of Biosciences, 57(11-12), 990993.

Jo, C., Son, J. H., Lee, H. J. \& Byun, M. W. (2003). Irradiation application for color removal and purification of green tea leaves extract. Radiation Physics and Chemistry, 66(2), 179-184. doi:10 . 1016 / S0969 806X(02)00273-6

Kim, M. J., Yook, H. S. \& Byun, M. W. (2000). Effects of gamma irradiation on microbial contamination and extraction yields of korean medicinal herbs. Radiation Physics 
and Chemistry, 57(1), 55-58. doi:10.1016/ S0969-806X(99)00298-4

Koseki, P. M., Villavicencio, A. L. C. H., Brito, M. S., Nahme, L. C., Sebastiao, K. I., Rela, P. R., .. Freitas, P. C. D. (2002). Effects of irradiation in medicinal and eatable herbs. Radiation Physics and Chemistry, 63(3-6), 681-684. doi:10.1016/S0969806X(01)00658-2

Lee, S. J., Umano, K., Shibamoto, T. \& Lee, K. G. (2005). Identification of volatile components in basil (ocimum basilicum 1.) and thyme leaves (thymus vulgaris l.) and their antioxidant properties. Food Chemistry, 91(1), 131-137. doi:10 . 1016/ j . foodchem.2004.05.056

Meda, A., Lamien, C. E., Romito, M., Millogo, J. \& Nacoulma, O. G. (2005). Determination of the total phenolic, flavonoid and proline contents in burkina fasan honey, as well as their radical scavenging activity. Food Chemistry, 91(3), 571-577. doi:10.1016/j. foochem.2004.10.006

Nagy, T. O., Solar, S., Sontag, G. \& Koenig, J. (2011). Identification of phenolic components in dried spices and influence of irradiation. Food Chemistry, 128(2), 530-534. doi:10.1016/j.foodchem.2011.03.037

Ott, R. L. (1984). An introduction to statistical methods and data analysis, 807-837.

Pellegrini, N., Serafini, M., Colombi, B., Del Rio, D., Salvatore, S., Bianchi, M. \& Brighenti, F. (2003). Total antioxidant capacity of plant foods, beverages and oils consumed in italy assessed by three different in vitro assays. Journal of Nutrition, 133(9), 28122819.

Pereira, E., Pimenta, A. I., Calhelha, R. C., Antonio, A. L., Verde, S. C., Barros, L., ... Ferreira, I. C. F. R. (2016). Effects of gamma irradiation on cytotoxicity and phenolic compounds of thymus vulgaris 1 . and mentha x piperita 1. LWT - Food Science and Technology, 71, 370-377. doi:10. 1016/j.lwt.2016.04.004

Perez, M. B., Calderon, N. L. \& Croci, C. A. (2007). Radiation-induced enhancement of antioxidant activity in extracts of rosemary (rosmarinus officinalis l.) Food Chemistry,
104(2), 585-592. doi:10.1016/j.foodchem. 2006.12.009

Polovka, M. \& Suhaj, M. (2010). Detection of caraway and bay leaves irradiation based on their extracts' antioxidant properties evaluation. Food Chemistry, 119(1), 391401. doi:10.1016/j.foodchem.2009.07.005

Senatore, F. (1996). Influence of harvesting time on yield and composition of the essential oil of a thyme (thymus pulegioides l) growing wild in campania (southern italy). Journal of Agricultural and Food Chemistry, 44(5), 1327-1332. doi:10.1021/jf950508z

Shurong, L., Meixu, G. \& Chuanyao, W. (2006). Use of irradiation to ensure hygienic quality of fresh pre-cut and blanched vegetables and tofu. Use of Irradiation to Ensure the Hygienic Quality of Fresh, Pre-Cut Fruits and Vegetables and Other Minimally Processed Food of Plant Origin, 87.

Singleton, Y. I. \& Rossi, J. A. J. (1965). Colorimetry of total phenolics with phophomolybdic-phosphotunstic acid reagents. Amer. J. Enol. Vitic, 16, 144158.

Suhaj, M., Rácová, J., Polovka, M. \& Brezová, V. (2006). Effect of ??-irradiation on antioxidant activity of black pepper (piper nigrum 1.) Food Chemistry, 97, 696-704. doi:10.1016/j.foodchem.2005.05.048

Taipina, M. S., Lamardo, L. C. A., Rodas, M. A. B. \& del Mastro, N. L. (2009). The effects of gamma irradiation on the vitamin e content and sensory qualities of pecan nuts (carya illinoensis). Radiation Physics and Chemistry, 78(7-8), 611-613. doi:10. 1016/j.radphyschem.2009.03.019

Variyar, P. S., Limaye, A. \& Sharma, A. (2004). Radiation-induced enhancement of antioxidant contents of soybean (glycine max merrill). Journal of Agricultural and Food Chemistry, 52(11), 3385-3388. doi:10. 1021/jf030793j

World Health Organization. (1988). Food irradiation: A technique for preserving and improving the safety of food.

Zhu, F., Cai, Y.-Z., Bao, J. \& Corke, H. (2010). Effect of gamma-irradiation on phenolic compounds in rice grain. Food Chemistry, 
120, 74-77. doi:10.1016/j.foodchem.2009. 09.072

Zin, Z. M., Abdul-Hamid, A. \& Osman, A. (2002). Antioxidative activity of extracts from mengkudu (morinda citrifolia l.) root, fruit and leaf. Food Chemistry, 78(2), 227231. doi:10.1016/S0308-8146(01)00402-2 